\title{
LAS PRÁCTICAS COMO APERTURA DE MUNDO: SEMÁNTICA, PRAGMÁTICA Y DIFERENCIA POLÍTICA
}

\author{
José Fernando García \\ Universidad Academia de Humanismo Cristiano \\ jgarcias@docentes.academia.cl
}

\begin{abstract}
Resumen / Abstract
El artículo se propone mostrar que las concepciones semántica y pragmática del significado, asumidas por Heidegger y Merleau-Ponty, respectivamente, dan lugar a interpretaciones disímiles de la diferencia la política-lo político, de gran difusión en el pensamiento contemporáneo. La tesis es que Heidegger y la llamada izquierda heideggeriana, LacoueLabarthe, Nancy, asumiendo la prevalencia epocal del inicio ontológico occidental, se comprometen con una concepción semántica, en último término esencialista. La historia de Occidente queda orientada por una metafísica identificada con la tecnología, con lo que, por una parte, la libertad subjetiva moderna y los derechos a los que da lugar quedan traslapados por aquella, y por otra, la política y lo político quedan escindidos y la primera es impotente para alterar lo segundo. Según la pragmática, sustentada entre otros por Merleau-Ponty, el significado no está dado por una previa apertura de mundo sino que va siendo establecido por un sentido inmanente a las prácticas, las cuales tienen el poder de abrir mundo. La filosofía, en este enfoque, tiene por tarea sustituir el sentido latente de las prácticas por un sentido manifiesto. En esa línea, Claude Lefort sostiene una concepción no esencialista de lo político, enfatiza la novedad de la democracia moderna y la relevancia de los derechos humanos.
\end{abstract}

Palabras Clave: semántica, pragmática, diferencia política, apertura de mundo, Heidegger, Lacoue-Labarthe, Nancy, Merleau-Ponty, Lefort

\section{PRACTICES AS WORLD'S OPENING: SEMANTICS, PRAGMATICS, AND POLITICAL DIFFERENCE}

The article aims to show that semantic and pragmatic conceptions of meaning, assumed by Heidegger and Merleau-Ponty, respectively, lead to dissimilar interpretations of the difference the political and politics, wide-spread in contemporary thought. The thesis is that Heidegger and the called heideggerians left, Lacoue-Labarthe, Nancy, assuming the prevalence of Western ontological epochal beginning, are committed to a semantic conception, ultimately essentialist. The Western history is guided by a metaphysics identified with technology, so that, first, modern subjective freedom and the rights that leads is overlapped by that, and secondly, that politics and the political remain split and the former is powerless to alter the latter. For pragmatics, supported among others by Merleau-Ponty, the meaning is not given by a previous opening world but is established by immanent meaning practices, which have the power to open world. Philosophy, in this view, has the task of replacing the latent sense of practices by a manifest sense. In that vein, Claude Lefort holds a non-essentialist conception of the political, emphasizing the novelty of modern democracy and the importance of human rights. 
KEY WORDS: semantic, pragmatic, political difference, world opening, Heidegger, LacoueLabarthe, Nancy, Merleau-Ponty, Lefort.

R⿴囗十 La diferencia de la política y lo político (la diferencia política en la jerga filosófica) ha adquirido en el pensamiento contemporáneo un lugar prominente, siendo asumida entre otros por filósofos como Claude Lefort, Phillipe Lacoue-Labarthe, Jean-Luc Nancy, Ernesto Laclau y Chantal Mouffe. Si bien fue introducida por Carl Schmitt en su famoso ensayo El concepto de lo politico, dichos autores se inspiran en la diferencia ontológica sostenida por Heidegger. La política, lo que usualmente se denomina de ese modo, suministra un fundamento contingente y temporal a lo social, sin que pueda suturar lo político. Este representa la dimensión 'ontológica', institucionalizante de la sociedad, reservándose el término política para las prácticas convencionales 'ónticas', intentos siempre fracasados de dar un fundamento a lo social (Marchart 2007).

Quisiera sostener a continuación que no obstante la común referencia al pensamiento de Heidegger, la diferencia política es elaborada de modo contrapuesto por aquellos filósofos que lo siguen en su concepción semántica del significado y los que han optado por una deriva pragmática.

Comienzo por mostrar que la diferencia óntico-ontológico tal como es elaborada por Heidegger tiene como consecuencia hipostasiar la ontología como un inicio que "prevalece sobre todo lo que ha de venir después" (Heidegger 2016: s/p) ${ }^{1}$, implicando una concepción semantica del significado, en último término esencialista. Eso tiene como consecuencia que la historia de Occidente sea pensada como un destino orientado por la metafísica identificada con la tecnología, uno de cuyos resultados es que la libertad subjetiva moderna quede traslapada por aquella (I). Enseguida arguyo que, consecuentemente con lo anterior, el modo en que lo que cabe llamar la izquierda heideggeriana -Philliphe Lacoue-Labarthe, Jean Luc Nancy- plantea la diferencia política tiene como efecto que la práctica política quede escindida de lo político, que la política sea impotente para alterar lo político, quedando condenada a reproducir un origen metafísico tecnológico-totalitario, y que los derechos humanos, la democracia y la ampliación de las libertades en la modernidad, sean vistas como prolongación de dicho origen (II). A continuación sostengo que Maurice Merleau-Ponty asume una perspectiva en la que el sentido es inmanente a las prácticas, entendidas como el entrecruzamiento de la acción con los otros y con la naturaleza, y en donde la filosofía sustituye el simbolismo tácito de la vida histórica por un simbolismo consciente, alejándose tanto de Heidegger como del estructuralismo (III). Finalmente, planteo que Claude Lefort toma distancia de todo esencialismo en su modo de pensar la diferencia política, asumiendo una concepción hermenéutico-pragmática del significado inspirada

El enunciado completo dice: "Porque el inicio de un destino es lo más grande. Prevalece sobre todo lo que ha de venir después". 
en Merleau-Ponty, en la cual las prácticas abren mundo, enfatizando la novedad de la democracia moderna y de los derechos humanos (IV).

Desde ya, quien es considerado el pensador que introduce la diferencia política, Carl Schmitt, no deja lugar a dudas de que persigue una definición de la esencia de lo político. En El concepto de lo político sostiene: "nos ocupamos de la esencia de 'lo político"'(Schmitt 2001: 171) Y más adelante agrega: “'Lo político' debe por eso consistir en alguna distinción de fondo a la cual puede ser remitido todo el actuar político en sentido específico" (Schmitt 2001: 177). Para Schmitt, una definición conceptual no ofrece una delimitación de un contenido sino un criterio equivalente a bueno y malo para la moral, bello y feo para la estética, rentable o no rentable para la economía, irreductible a ninguno de los anteriores.

Un criterio es una norma o un juicio, con lo que Schmitt se ubica inequívocamente en una posición nominalista, distanciándose de toda metafísica. No obstante, invertir meramente el orden tradicional, poniendo el juicio antes del concepto, no impide que la metafísica de la esencia continúe su trabajo. Los términos empleados por Schmitt, concepto, definición, esencia, no son, pues, arbitrarios sino que están entretejidos. Quien, tal vez, lo ha puesto de manifiesto con mayor lucidez sea Ernst Cassirer. De acuerdo con su análisis, en la teoría tradicional toda construcción de conceptos consiste en seleccionar de una pluralidad propiedades similares, ignorando el resto. Pero el concepto perdería todo valor si significara meramente la exclusión de los casos particulares de los que parte y la negación de su particularidad. Por el contrario, el acto de exclusión significa un proceso positivo; lo que permanece no es simplemente una parte escogida arbitrariamente sino un momento esencial por el cual el todo es determinado. Es claro que esta regla general de formación de conceptos no es suficiente, requiere una tácita referencia a otro criterio. En la lógica de Aristóteles este criterio es evidente: el vacío que hay en la lógica es llenado por la metafísica y la doctrina del concepto es el vínculo que mantiene ambos campos juntos. La selección de lo que es común permanecería como un juego de ideas vacío si no se asume que lo que se ha ganado es, al mismo tiempo, la forma real que garantiza la conexión causal y teleológica de las cosas particulares. De modo que la doctrina tradicional de construcción de conceptos y de la definición solo puede ser sostenida, explícita o implícitamente, en referencia a esa relación fundamental de lo real. De allí que Cassirer oponga a dicho concepto que representa el punto de vista de la substancia, el concepto matemático de función en las ciencias naturales. En éste no se aísla ninguna parte abstracta de una multiplicidad sino que se crea entre sus miembros una relación a través de una ley constructiva (Cassirer 1953).

Quisiera sostener a continuación que el sesgo esencialista permanece en la deriva heideggeriana de la diferencia política. La diferencia ontológica en Heidegger implica que la proposición es modo derivado de la interpretación. La proposición es la declaración o afirmación de la relación de algo sobre algo, pero el "algo en cuanto algo" no viene dado por la proposición sino que es un presupuesto de ésta, el "como 
apofántico" supone el "como hermenéutico", una interpretación del ser de los entes. El término interpretación tiene para Heidegger un significado que remite a la comprensión: la interpretación es la elaboración de las posibilidades proyectadas en el comprender; no es nunca la aprehensión sin supuestos de algo. La interpretación de algo como algo se funda en el haber previo (Vorhabe), en la manera previa de ver (Vorsicht) y en la manera de entender previa (Vorgriff). Por haber previo, Heidegger entiende la totalidad comprensional implícita, la cual requiere, para ser apropiada, de la manera previa de ver o de un punto de vista que "recorta" lo dado en el haber previo. A su vez, la manera de entender previa se refiere a los conceptos que permiten interpretar aquello recortado por la manera previa de ver.

De modo que toda interpretación se lleva a cabo a partir de una comprensión previa y Heidegger recuerda que esto es conocido desde antiguo, preferentemente en el terreno de la filología. Pero entra en conflicto con la concepción de demostración científica prevaleciente en la modernidad. La demostración científica no debe presuponer lo que ella tiene que demostrar. No es posible, sin embargo, evitar el círculo de la comprensión, toda vez que corresponde a la estructura existencial del Dasein.

Ahora, ¿qué modificaciones ocurren con la tematización que se encierra en una proposición? ¿Cómo se transita del "como hermenéutico" al "como apofántico"? La proposición en cuanto conducta de una existencia es también un "tener que ver con", tratar sobre algo. Sin embargo, este "tener que ver con" se retira, por así decirlo, de la función primaria, por ejemplo, la tiza del escribir. Pero eso significa que la comprensión no reside ya en el cumplir la función ni en su utilidad sino que ahora el "tener que ver con" se limita a algo solo presente, a la tiza en cuanto tiene ciertas propiedades como extensión, peso, forma, etc. La tiza queda nivelada como mera cosa y en tanto que es esta cosa presente no se distingue de cualquier otra cosa. Ahora bien, de acuerdo con Heidegger, el fundamento de la lógica tradicional se orienta por este hacer presente, lo cual se expresa en que para los griegos y la tradición posterior el conocimiento sea teoría e intuición, traer a presencia.

Pero el determinar proposicional nunca es un descubrir primario y por eso este $\lambda$ ó $\gamma \circ \varsigma$ no puede ser el hilo conductor de la pregunta acerca de qué es el ente, el fenómeno del determinar no puede constituirse en el punto de partida para la pregunta por el ser, puesto que esa pregunta ha de capturar el fenómeno desde su raíz. El fenómeno originario de la verdad es el develar como apertura de mundo que pone al descubierto a los entes intramundanos. La proposición no es aquello en lo que la verdad se hace posible, sino al revés: la proposición es posible en la verdad. "La proposición no es el lugar de la verdad, sino que la verdad es el lugar de la proposición” (Heidegger 2004: 113).

La apertura de mundo es, pues, constitutiva del acceso a los entes intramundanos, determina lo que puede salirnos al encuentro en el mundo. Solo en la comprensión previa del ser puede revelarse el ente en su qué y en su cómo. "Pero lo óntico patente acontece en un encontrarse en medio del ente (Sichbefinden) impulsivo y conforme al temple de ánimo, y en las actitudes hacia el ente co-fundamentadas en la aspiración y la volición. Pero ni aun éstas son capaces -sea que se interpreten como antepredicativas o como predicativas- de hacer accesible al ente en sí mismo, si su patencia no está ya de antemano iluminada y orientada por una comprensión del ser del ente" (Heidegger 
1992: 67-68) ${ }^{2}$. Ahora bien "qué es algo y cómo es, es lo que llamamos su esencia" (Heidegger 1995: 11). De este modo, la interpretación del ser de los entes, la apertura de mundo, queda hipostasiada, toda interpretación queda encerrada en el círculo de una apertura de mundo, sin que las prácticas lingüísticas puedan abrir mundo, lo que supone una concepción semantica del lenguaje ${ }^{3}$.

Como ha sido reconocido por el mismo Heidegger, Ser y tiempo mantenía una ambigüedad: por una parte, la cuestión del ser habría caído en el olvido desde el surgimiento de la filosofía en Grecia -"sobre la base de los comienzos griegos de la interpretación del ser, llegó a constituirse un dogma que no solo declara superflua la pregunta por el sentido del ser, sino que, además, ratifica y legitima su omisión" (Heidegger 1997: 25)-; por otra parte, el ocultamiento del mundo y, por tanto, el olvido de la pregunta por el ser responden a un comportamiento del Dasein: "como en este absorberse en el mundo se pasa por alto el fenómeno mismo del mundo, vienen a ocupar su lugar los entes que están-ahí dentro del mundo, las cosas" (Heidegger 1997: 154). El fenómeno del 'uno' es un existencial, esto es, corresponde a un modo de ser del Dasein que Heidegger distingue del sí-mismo propio, el cual "exige, pues, que una interpretación ontológica" (....) "conquiste para sí el ser de este ente en contra de la tendencia encubridora que hay en él” (Heidegger 1997: 304).

Esto último dio lugar a una interpretación antropológica de Ser y tiempo que en los años 30 Heidegger resuelve enfáticamente a favor de una concepción de la historia como un "girar" metafísico entendido como humanismo. "El comienzo de la Metafísica,

2 El énfasis es agregado.

3 Tanto Gadamer como Habermas han puesto de manifiesto la orientación semántica de Heidegger. “Así, pienso que en cierto sentido Derrida ha seguido la senda del pensamiento de Heidegger mucho más que yo. Me parece que esta senda está marcada por una dependencia ontológica no aclarada del punto de partida semántico implicado en su perspectiva del lenguaje" (Gadamer, Derrida 1989: 125). "De este modo, aunque partiendo de puntos contrapuestos, la filosofía analítica y la hermenéutica se han limitado al aspecto semántico, por una parte a la relación entre proposición y hecho, y por otra a la articulación conceptual del mundo que es inmanente a un lenguaje natural" (Habermas 2002: 77). A su vez, Cristina Lafont sostiene que la diferencia ontológica, entendida al modo de Heidegger, implica una teoría del significado que ella, inspirada en la obra de Hilary Putnam, ha denominado "intensionalismo", esto es, que la intensión determina la extensión de los conceptos. Según Lafont, esto implica que el sentido a partir del cual algo es comprensible como algo posee un papel constitutivo para el acceso a los entes intramundanos en cuanto tales, de forma que se convierte así en determinante a priori de todo conocimiento que se adquiere a posteriori y no es revisable a través de éste (Lafont 1997).

4 "Sentido, Sinn, tiene en Ser y Tiempo una significación muy precisa, incluso si hoy se ha vuelto insuficiente. ¿Qué quiere decir Sinn von Sein (sentido del ser)? Esto se comprende a partir del dominio de proyecto (Entwurfsbereich) que despliega la comprensión del ser (Seinsverständnis). Comprensión, Verständnis, debe a su vez ser entendida en el sentido primario de Verstehen: estar de pie ante, estar a nivel de, ser capaz de sostener eso ante lo que se está. Sinn se comprende a partir de Entwurf, que se explica por Verstehen. El 
en el pensamiento de Platón, es, a la vez, el comienzo del 'humanismo'. Tómese aquí esta palabra esencialmente, $y$, por tanto, en su más abarcante significación. Según ella significaría "humanismo" ese acontecimiento, -conexo con el principio, con el desarrollo y con el final de la metafísica-, por el que el hombre, de diversas maneras, a sabiendas siempre, se implante en una cierta posición central dentro del ente, sin llegar a ser, por tal hecho, el ente supremo" (Heidegger 2016a: 19).

Con ese viraje, la historia de Occidente queda entendida como un destino metafísico frente al cual solo cabe la espera del acontecimiento que produzca una mutación de la interpretación del ser de los entes 5 . En este punto Heidegger es enfático: "El tipo de historia de la historia de lo Ser se determina evidentemente por la manera como Ser acontece, y solo por esa manera; esto quiere decir, según lo expuesto anteriormente, por el modo como Se da Ser” (Heidegger 2003: 281). Consecuentemente, “..... todo obrar reside en el ser y se orienta a lo ente" (Heidegger 2000: 12).

Para Heidegger, la Época Moderna es la época en la cual el humanismo se despliega sin límites como técnica mecanizada, una transformación autónoma de la práctica que exige, a su vez, a la ciencia matemática de la naturaleza. "La técnica mecanizada sigue siendo hasta ahora el resultado más visible de la esencia de la técnica moderna, la cual es idéntica a la esencia de la metafísica moderna" (Heidegger 1998: 63). En la modernidad el hombre se convierte en el auténtico subjectum, esto es, en el ente sobre el que se fundamenta todo otro ente en lo tocante a su modo de ser y a su verdad, en centro de referencia de lo ente como tal. "Se busca y encuentra el ser de lo ente en la representabilidad de lo ente" (Ibíd: 74). Heidegger menciona de paso que la Época Moderna puede ser vista correctamente como el tiempo en el que el hombre se libera de las ataduras medievales, pero entiende que dicha consideración es superficial y que lo esencial es el juego alternante y necesario entre subjetivismo y objetivismo que caracteriza a dicha época.

La libertad subjetiva queda, de este modo, traslapada por la técnica como esencia de la época moderna y la autonomía de la voluntad, los derechos humanos, la democracia, a los que da origen, como una manifestación más de la misma. Para Heidegger la libertad es un valor y "la pregunta por el valor y por su esencia se funda en la pregunta por el ser" (2000a: 46). La libertad moderna vista metafísicamente es el ponerse el hombre a sí mismo como vinculante "y puesto que este volverse señor requiere el poder en un sentido esencial y expreso, por eso el esencial dar poder al poder solo

inconveniente de este abordaje es que deja demasiado abierta la posibilidad de entender el proyecto (Entwurf) como una performance humana, siendo que nada tiene que ver aquí el proyecto como estructura de la subjetividad -lo que hace Sartre apoyándose en Descartes (en

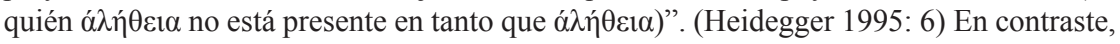
en el curso titulado "Lógica" del verano de 1928 y publicado como The metaphysical foundations of logic, dice: "La cuestión básica de la filosofía, la cuestión del ser, es en sí misma correctamente entendida, la cuestión del hombre" (Heidegger 1992: 16).

"Pues, precisamente el hombre llega a ser libre en tanto que pertenece al ámbito del destino y, así, llega a ser un oyente, no un esclavo” (Heidegger 2003: 135). 
es posible como realidad fundamental en la historia de la época moderna y como esa historia (....). El 'poder', rectamente entendido en su sentido moderno, es decir como voluntad de poder, solo se vuelve metafísicamente posible como historia moderna" (Ibíd.: 121). La libertad moderna solamente puede dar lugar al cálculo, a la voluntad de poder y a la tecnología, cuyos productos son la ciencia y el Estado, con lo que se cierra la posibilidad de toda reflexión sobre la ética, los derechos y la normatividad ${ }^{6}$.

Quien paradójicamente pone de manifiesto la unilateralidad de la posición de Heidegger es Carl Schmitt. Éste ve igualmente en el Estado moderno un producto de la tecnología: "El Estado como totalidad es, con su cuerpo y alma, un homo artificialis y, como tal máquina. Es una obra fabricada por los hombres, en la que el material y los artífices, la máquina y su constructor, son los mismos, es decir, hombres" (Schmitt 1990: 34). Pero contrariamente a Heidegger, Schmitt advierte en la libertad subjetiva no solamente una voluntad de poder - una razón calculante que fabrica el Estado- sino también un límite al poder de ese Estado que, por cierto, de acuerdo a su opción política, lamenta. La distinción hobbesiana entre creencia interna y la confesión externa, la oposición entre razón pública y razón privada respecto a la creencia en los milagros, el reconocimiento de que "el pensar es libre", pone un límite al poder del soberano. "La distinción de lo privado y lo público, entre la fe y la confesión, fides y confessio, faith y confesión, ha calado tan hondo, que de ella se han derivado consecuentemente en el curso de los siglos posteriores el Estado de derecho y el Estado Constitucional Liberal" (Ibíd.: 55). La perspectiva de Schmitt permite reconocer en la obra de Hobbes lo que se puede llamar las dos caras de la modernidad, ambas originadas en la subjetividad: por una parte, de la técnica mecanizada como voluntad de poder, por otra, de un fuero interno en el que los poderes externos no pueden penetrar, el que da origen a la libertad subjetiva y a los derechos que ésta supone, reivindicados ya tan tempranamente como el siglo XVII en la obra de Spinoza (José Fernando García 2015).

Philippe Lacoue-Labarthe y Jean-Luc Nancy sostienen claramente que su proyecto trata de establecer la esencia de lo político. El siguiente pasaje no deja lugar a dudas que piensan la esencia en el mismo sentido que Heidegger, como una apertura de sentido, una precomprensión que pone límites o define un ámbito del cual los conceptos serían una derivación: “¿Cuál es el problema general de lo político? ¿cuál es el origen, cuáles son los puntales, cuales los límites o cuál el ámbito del concepto(s) de lo político que manejamos? ¿En qué consiste lo político en su esencia?” (Lacoue-Labarthe 1989:

6 "La ciencia moderna y el Estado total, en su calidad de resultados necesarios de la esencia de la técnica, son también su consecuencia" (“¿Y para qué poetas?”, en Heidegger 1995: 215). 
270). Consecuentemente, la interrogación sobre la esencia de lo político es una tarea exclusivamente filosófica, no hay ninguna pretensión de hacer teoría política, ni ciencia política ni politología, consideradas tareas que tratan con lo meramente empírico u óntico.

Para estos autores hay un implicación recíproca entre lo filosófico y lo político que define nuestra situación caracterizada por lo que llaman "el efecto memorial o mimético del 'envío' metafísico griego, esto es, la calificación de lo político por el sujeto y del sujeto por lo político. Prefieren el término "lo filosófico" para referirse a la metafísica en la significación que le da Heidegger, caracterizándola del siguiente modo: "Si lo prefieren, lo filosófico designa una estructura histórico-sistemática-general -lo que podría ser llamado Occidente hasta estos últimos tiempos- de la cual la filosofía es en cada caso la tematización, la prefiguración o la anticipación, la reflexión (crítica o no), la refutación, etc., pero que desborda ampliamente el campo de ejercicio en el fondo muy restringido del filosofar propiamente dicho" (Lacoue-Labarthe, Nancy 1997: 124). Esto autorizaría a hablar desde los griegos de la co-pertenencia de lo filosófico y de lo político: la interrogación sobre la esencia de lo político implica remontarse hasta los presupuestos políticos de la filosofía, a la institución política del pensamiento occidental.

El cuestionamiento a la filosofía como lo político o acerca de lo político supone reconocer la clausura de lo filosófico y lo político en un sentido no sin relación con los análisis de Heidegger acerca de la tecnología. Lo que estaría llegando a su fin es el discurso progresista-ilustrado de una escatología secular o profana, el discurso de la actualización del género de lo humano. En la época en que la política ha llegado a excluir toda otra área de referencia -lo que corresponde al fenómeno del totalitarismo mismo- no cabe ofrecer soluciones políticas a la humanidad, dado que se conocen ahora qué promete el deseo de transparencia social, la utopía de la homogeneización del cuerpo social, la esperanza vinculada a la administración y a la dirección ilustrada. La clausura, en la acepción heideggeriana que los autores asumen, no se sobrepasa, si hay un más allá del límite, este más allá no es discernible, su lado externo se deja entrever o adivinar solamente como algo negativo o innominado (Lacoue-Labarthe 2002: 17; Nancy 2009: 67).

Se resisten a hablar, sin embargo, con Heidegger de lo político como tecnología y prefieren denominarlo "totalitarismo", en la línea de Arendt, y sostienen que "el totalitarismo es el horizonte insuperable de nuestro tiempo" (Lacoue-Labarthe y Nancy 2000: 37), no dejando de mencionar que la ética y los derechos humanos es algo "inesencial y subalterno" (Lacoue-Labarthe 2002: 19). El fenómeno totalitario designa la clausura o término de lo político que se confunde con el reino integral de la política, con exclusión de todo otro dominio, bajo la consigna "todo es político" (Lacoue-Labarthe y Nancy 1997: 95 y ss.). Este dominio de lo político se oculta, como aquello entendido por sí mismo, de allí el término "retiro" que introducen, en un sentido similar al "abandono del ser" u "olvido del ser" heideggerianos. Pero eso mismo permite plantear la cuestión de una nueva manera, esto es, la cuestión de su esencia (Lacoue-Labarthe y Nancy 1997: 112). Los autores no dejan de recordar que esta caracterización del fenómeno totalitario rompe con todo tratamiento y sostén empírico. Esto bajo la clausura de lo filosófico en 
su figura moderna, esto es, de las filosofías del Sujeto ${ }^{7}$. No obstante, traen a colación algunos hechos, como la desaparición de toda especificidad de la política, así como del espacio público, señalado con insistencia por Arendt. Al mismo tiempo "totalitarismo" se refiere a los regímenes fascista, nazi y estalinista y aquí el énfasis está puesto en el delirante intento de re-substancialización, re-encarnación o re-organización del cuerpo social. Sin rechazar esa concepción del totalitarismo, los autores se preguntan si una forma más "suave" de totalitarismo no se ha instalado sin nuestro conocimiento, si bajo el manto de la dominación tecnológica no estarán ocurriendo procesos de resubstancialización del cuerpo político, una homegeneización del "pueblo que sufraga", una intensa fabricación de consensos y una difusa ideología psicologizante.

Es más, de acuerdo con Lacoue-Labarthe, habría que dejar de considerar el nazismo como un fenómeno patológico y verlo como "la mejor forma política hoy mismo, en cuanto que nos aclara sobre la esencia de lo político en la modernidad" (Lacoue-Labarthe 2002: 125). El nazismo recoge una herencia filosófica, deformada o degradada cuanto se quiera, que ha sido ignorada. "Pero tampoco hay aquí que equivocarse, el nazismo es un humanismo en tanto que se basa en una determinación de la humanitas más poderosa a sus ojos, es decir, más efectiva que cualquier otra. El sujeto de la autocreación absoluta, incluso si trasciende todas las determinaciones del sujeto moderno dentro de una posición inmediatamente natural (la particularidad de la raza), reúne y concreta esas mismas determinaciones (como también lo hace el estalinismo con el sujeto de la autoproducción absoluta) y se instituye como el sujeto como tal" (Ibíd.: 111-112).

La democracia estaría en proceso de secretar una nueva forma de totalitarismo, cuyas características son: 1) La victoria del animal laborans, del hombre definido como trabajador o productor. 2) La recuperación del espacio público por lo social. 3) La pérdida de la autoridad como elemento distintivo del poder.

La característica del nuevo totalitarismo -el retiro de lo político- sería la disolución de la trascendencia -el inmanentismo, en la terminología de Nancy-, la cual penetra todas las esferas de la vida social, que quedan desprovistas de alteridad. No se trata, por cierto, de recuperar las antiguas formas de trascendencia sino de "desplazar, reelaborar y volver a plantear el concepto de "trascendencia política", y ésta es una tarea relativa a la esencia de lo político (Lacoue-Labarthe 2002: 130).

¿Dónde se originaría esa trascendencia? Lacoue-Labarthe y Nancy mencionan tres ámbitos: 1) La articulación del poder, como fuerza material que constriñe, con la autoridad. 2) La relación de la comunidad con la inmortalidad en este mundo. 3) La

7 Que Nancy ve inaugurado en mayo del 68: "Esto también quería decir: ya no una verdad venidera, objeto de una intención y una voluntad, sino una verdad en presente, la verdad que está más allá del proyecto (que lo funda, sin duda, pero que éste no puede satisfacer); algo así como una afirmación de ser en el mundo a despecho de todos los proyectos a construir o alumbrar el sentido del mundo. En este aspecto, el 68 ha sido mucho más 'metafísico' o 'espiritual' que social, político, cultural o lo que fuere” (Nancy 2009: 66). 
relación de la comunidad a sí misma o la manifestación de lo social a sí mismo como ser-en-común ${ }^{8}$.

Para Nancy lo que se anuncia el 68 es el fin no solamente de la "época de las concepciones del mundo" sino también del trazado de horizontes, la determinación de objetivos y la previsión operativa, el abandono, en definitiva de la era de la historia, o "ya no una historia en la cual fuésemos los sujetos, sino una historia que nos sorprendiera y nos arrebatara" (Ibíd.: 65), que es para Nancy inseparable del evento, "el evento sorprende o no es un evento" (Nancy 2000a: 97). En el 68, de diversas maneras, se abandonaba el régimen de la "concepción" para abrir otro régimen de pensamiento: ya no más formas encargadas de modelar un dato histórico preformado como "progreso" y de inspeccionar las cosas en nombre de la razón. Lo que cuenta es esta verdad: que la autoridad no puede ser definida por ninguna autorización previa y solo puede proceder de un deseo que se expresa o reconoce en ella. La democracia no debe disponer de autoridad alguna identificada a partir de un lugar diferente a un deseo en el cual se exprese y reconozca una verdadera posibilidad de ser todos juntos en común. La comunidad no es un ser en común sino un ser en común, estar uno con otro. Lo que significa que puedo decir "yo" solo si puedo decir "nosotros", la alteridad consiste en la no presencia a sí: "Somos otros - cada uno para el otro y cada uno para sí- por el nacimiento y la muerte que exponen nuestra finitud o que hoy exponen $a$ la finitud" (Nancy 2000: 176).

No obstante ese anuncio del 68, en la carta de suspensión de las actividades del Centre de Recherches Philosophiques sur le Politique, el año 1984, Lacoue-Labarthe y Nancy lamentan un consenso al cual la producción del propio centro no ha podido escapar y que parece echar tierra sobre todo "anuncio". Lo expresan del siguente modo: "A nuestro juicio, como al de muchos de los otros participantes o colaboradores, este tipo de trabajo presupone que ninguna certeza, vieja o nueva, a toda prisa, podría sellar la brecha abierta en lo que podríamos llamar la mentalidad general de nuestro tiempo por la de-posición de lo político. Lo cual, en concreto, significa esto: que nada de lo político se estableció a partir de ahora, ni siquiera y sobre todo su liquidación o su cancelación de Occidente y su metafísica" (Lacoue-Labarthe, Nancy 1997: 144). Dos son las consecuencias de esto: en primer lugar, la anulación de todo cuestionamieto a la esencia de lo político, traducido en que ésta se ve simplemente sumergida en la esencia metafísica de Occidente, como voluntad de dominio, lo que, en segundo lugar no deja lugar alguno para la elección política (Ibíd.: 146). Años más tarde (1996), Nancy reafirma esto último, a su manera. Se pregunta “¿Qué se debe hacer?” y su respuesta es la siguiente: "Tal vez, pensamos más o menos discretamente para nosotros mismos, tal vez la incertidumbre de 'lo que se debe hacer' es hoy tan grande, tan fluctuante,

8 "Debemos decidirnos a -y cómo- estar en común, cómo permitir a nuestra existencia existir. No sólo es cada vez una decisión política, es una decisión a propósito de lo político; si y cómo permitimos a nuestra alteridad existir en conjunto, inscribirse como comunidad e historia" (Nancy 2000: 188). "Y, en consecuencia, recuperar el sentido de lo que es estar juntos, ser-con, sin atribuirle un carácter inmediatamente político" (Nancy 2009: 103). 
tan indeterminada, que no necesitamos ni siquiera hacer esto: plantearnos la pregunta" (Ibíd.: 157).

Todo esto es un síntoma de las dificultades para pensar la política tomando como referencia el pensamiento de Heidegger". Tal vez por eso en la "Nota de 2014" a la reedicion de La conferencia de Heidelberg llevada a cabo en febrero de 1988, con la participación de Gadamer, Derrida y Lacoue-Labarthe, entre otros, Nancy parece inclinarse hacia lo que podría interpretarse como una postura pragmática afín a la de Gadamer y Merleau-Ponty, tomando distancia de la hipóstasis 'del ser' heideggeriano. Refiriéndose a Heidegger escribe: "Lo que él era capaz de pensar se condensa en la frase en la que Gadamer dice que hablar de 'el ser' con artículo 'es ya una falsificación'. Esta es una manera perfecta de describir el recurso esencial de este pensamiento". Y continúa más adelante: "Porque a partir de 'ser' sin artículo no se puede ir -no de la misma manera por lo menos- en el camino de este 'olvido del ser' que ha obnubilado a Heidegger hasta el punto de embalar en este 'olvido' la doxa más banal sobre el capitalismo y la tecnología, el agotamiento de Occidente y la designación de un agente pernicioso llamado 'judío' como opción de una cultura que construía el chivo expiatorio exigido por la secreta repulsión de sí misma" (Derrida, Gadamer, Lacoue-Labarthe 2014: 13).

Maurice Merleau-Ponty en su polémica con Marx y el marxismo (Merleau-Ponty 1957 y 2006) defiende lo que llama 'la unión de la filosofía y de la historia', orientada a suprimir la mutua exclusión de una y otra. Ni la historia como un destino exterior en beneficio del cual el filósofo tendría que suprimirse, ni la autonomía filosófica separada de la historia; ni la filosofía ni la historia como tradiciones rivales, es el reclamo de Merleau-Ponty. "Pues, tomadas en estado naciente, en la práctica humana, no constituyen una alternativa, crecen y decrecen juntas"(Merleau-Ponty 2006: 32). Rescata del Marx jóven la praxis entendida como el sentido que se establece espontáneamente en el entrecruzamiento de la acción con los otros y con la naturaleza. El sentido histórico es inmanente a las interacciones y frágil como ellas; la contingencia de los sucesos humanos no son un defecto de la historia sino su condición. La historia no tendría sentido comprendida como un río que corre bajo la acción de causas todopoderosas; toda apelación a la historia universal corta el sentido de los acontecimientos, volviendo insignificante la historia efectiva.

Merleau-Ponty ve renacer la unión de la filosofía y la historia en la moderna lingüística de Saussure. "En el acto de hablar, en su tono y en su estilo, el sujeto

9 "El problema consiste en que Heidegger intenta reconstruir filosóficamente la historia, incluida la historia política, de modo que la suya es una política esencial" (García de la Huerta 2015: 81). 
atestigua su autonomía, ya que nada le es más propio y, sin embargo, él está al mismo tiempo y sin contradicción vuelto hacia la comunidad lingüística y es tributario de la lengua" (Merleau-Ponty 2006: 36). Sostiene enfáticamente: "el poder que tienen los sujetos hablantes para sobrepasar los signos hacia el sentido" (Merleau-Ponty 1964: 95). Cada acto parcial de expresión, como acto común del todo de la lengua, no se limita a expresar un poder expresivo acumulado en ella sino que lo recrea. "Los signos no solamente evocan para nosotros otros signos y así sucesivamente, el lenguaje no es una especie de prisión en la que estemos encerrados, o una especie de guía que habría que seguir ciegamente, puesto que, en la intersección de todos esos gestos lingüísticos, aparece por fin lo que quieren decir y a qué nos dispone un acceso tan completo que nos parece no tener ya necesidad de ellos para referirnos a él" (Ibíd.).

La unión de la filosofía y de la historia, tal como Merleau-Ponty la entiende, es una vía que que se separa tanto del estructuralismo -el cual enfatiza que "la lengua no es una función del sujeto hablante" (Saussure 1995: 30) ${ }^{10}$ - como de Heidegger: "en su esencia el habla no es ni expresión ni actividad del hombre. El habla habla" (Heidegger 1987: 17), las dos fuentes del antihumanismo en el pensamiento contemporáneo. Merleau-Ponty no está, por cierto, reivindicando el humanismo criticado por Heidegger y los estructuralistas, que pone al hombre en una posición dominante ante al resto de los entes, al modo de un sujeto desvinculado frente al mundo como objeto. Igualmente que la lengua, las instituciones constituyen sistemas simbólicos al que los agentes se incorporan sin necesariamente concebirlos. Las rupturas de equilibrio, las reorganizaciones que ocurren suponen, como en la lengua, una lógica interna no pensada por nadie. El sistema simbólico lleva a efecto los cambios de un modo que escapa a la dicotomía entre cosa e idea.

¿Cuál es la relación de la filosofía con esos sistemas simbólicos? Para MerleauPonty la filosofía sustituye el simbolismo tácito de la vida histórica por un simbolismo consciente, un sentido latente por un sentido manifiesto. La filosofía no se contenta con sufrir el entorno histórico - tanto como éste con sufrir su pasado- y revelándolo a sí mismo lo cambia. La filosofía se vuelve hacia la actividad simbólica anónima de la cual emergemos y hacia nuestro discurso. Trata de aprehender los momentos en los

10 El siguiente pasaje de Saussure avala la interpretación de Merleau-Ponty: "De este modo la lingüística se encuentra aquí ante su segunda bifurcación. Primero hubo que elegir entre la lengua y el habla, henos aquí ahora en la encrucijada de rutas que conducen, una a la diacronía, otra a la sincronía. (....) Una vez en posesión de este doble principio de clasificación puede añadirse que todo lo que es diacrónico en la lengua lo es solamente por el habla. Es en el habla donde se encuentra el gérmen de todos los cambios: cada uno de ellos es lanzado primero por cierto número de individuos antes de entrar en el uso" (....). "Pero no todas las innovaciones del habla tienen el mismo éxito, y mientras sigan siendo individuales no hay que tenerlas en cuenta, dado que nosotros estudiamos la lengua, solo entran en nuestro campo de observación en el momento en que la colectividad las acoge" (Saussurre 1995: 138). 
que el sentido toma posesión de sí mismo e impulsa más allá de todo límite el devenir de verdad que éste supone (Merleau-Ponty 2006: 37 y ss.).

Claude Lefort se propone repensar la política a partir de la experiencia de nuestro tiempo, distanciándose de todo intento de establecer una definición de la misma. “¿No es necesario, más bien, convenir que toda tentativa de fijar la esencia de la política interfiere el libre movimiento del pensamiento y que éste, por el contrario, no se sostiene más que a condición de no prejuzgar los límites de la política, de consentir una exploración cuyos caminos no son conocidos previamente?" (Lefort 1986: 7). Entiende que esa es una tarea propia de la filosofía política, dado que la ciencia y la sociología políticas circunscriben la política diferenciándola de otros dominios como lo social, lo económico, lo jurídico, lo religioso, siguiendo los imperativos de un conocimiento positivo, neutral y objetivo. La investigación que se propone Lefort prohíbe pensar la política como un sector particular de la vida social e implica conocer un conjunto de principios generadores de las relaciones que los hombres mantienen entre sí y con el mundo, conjunto al que denomina forma de sociedad. En este concepto "se combinan la idea de un tipo de constitución y la de un estilo de existencia o de un modo de vida" (Lefort 1986: 9). Por constitución Lefort entiende una estructura legítima de poder y por estilo de existencia, un conjunto de normas implícitas que establecen qué es justo o injusto, bueno o malo, deseable e indeseable, noble y vil, esto es, el concepto forma de sociedad apunta a una necesaria institución política de lo social. De modo que lo político se revela no en lo que comúnmente se llama 'política' sino en un doble movimiento de aparición y ocultamiento del modo de institución de la sociedad: es visible aquello que ordena y unifica a la sociedad, mientras se oculta el principio de su configuración (Lefort 2004).

En esta tarea, Lefort cree necesario situarse en relación con Hannah Arendt, "una de las raras autoras que quiere devolver pleno sentido a la noción de la política" (Lefort 1986: 13). Comparte con ella la convicción de que los eventos del siglo XX, especialmente el surgimiento de los regímenes totalitarios, plantean al pensamiento la necesidad de un re-comienzo. No participa, sin embargo, de la convicción de Arendt de que dichos eventos han echado por tierra todas las categorías del pensamiento occidental y que éste deba romper con toda la tradición de la filosofía política. La decisión de separarse de toda la tradición va acompañada de la certidumbre, por parte de Arendt, de una definición de la política. "Así, todas sus investigaciones están subordinadas a la idea clara y distinta de qué es política y qué no lo es” (Ibíd.). Y de ahí sus oposiciones rígidas entre la esfera de lo social y la esfera de lo político, entre el dominio privado y el dominio público, entre la existencia del individuo y del ciudadano. Y de ahí también su convicción de la corrupción creciente de la democracia moderna, la que haría surgir de su seno mismo el totalitarismo. "Buscamos, -dice Lefort-siguiendo ciertos caminos, las huellas de la política, en los hechos, los actos, las representaciones, en las relaciones 
que no hemos asignado de oficio a tal o cual registro determinado de nuestra 'condición'. Atento a los signos de la repetición como a aquellos de lo nuevo, nos restringimos a detectar la dimensión simbólica de lo social" (Ibíd.: 14).

Lefort se aleja, con esas precisiones, del imperio "del inicio" heideggeriano, bajo el cual se encuentra la obra de Arendt, asumiendo una posición hermenéuticopragmática, como lo revela inequívocamente, además del inmediatamente anterior, el siguiente pasaje: "Si intentamos concebir otro modo de la relación con lo político, debemos empezar por reconocer que su figura se está esbozando ante nuestros ojos. Por eso, la primera tarea no es inventar, es interpretar, elevar a la reflexión una práctica que ciertamente no es muda pero que por necesariamente difusa, ignora su alcance en la generalidad de lo social y de la que por naturaleza no pueden extraer su verdad aquellas formaciones políticas que solo se dedican a usarla y, en parte, y no sin éxito, a desarmar" (Lefort 2004: 207) ${ }^{11}$.

Para Lefort, el carácter simbólico de lo social testimonia el surgimiento de una forma de sociedad en Occidente relativamente nueva y que cabe distinguir de todas las anteriores. Sobre el telón de fondo de las sociedades pre-modernas y del totalitarismo moderno, la democracia aparece como lo que Lefort llama "una mutación de orden simbólico", cuya característica fundamental es que el poder se convierte en un lugar vacío y su ejercicio debe someterse a una revisión periódica. Este fenómeno implica la institucionalización del conflicto y supone una separación entre un interior y un exterior a lo social. El derecho y el conocimiento se afirman frente al poder como exterioridades irreductibles, sin puntos de inserción; el derecho queda abierto a un debate sobre su legitimidad y fundamento, y el conocimiento, a una revisión permanente.

"Pero allí donde el derecho está en cuestión, la sociedad, esto es el orden establecido, también lo está" (Lefort 2004: 203). Desde el derecho de huelga y los derechos sindicales hasta la seguridad social, hay toda una historia de transgresión de las fronteras, ensanchadas progresivamente, que no reconocen límites dados, desprovistos de garantías objetivas, afirmados en referencia a los principios de los derechos humanos públicamente reconocidos, movilizados para ir más allá de los obstáculos legales vigentes. La democracia en nuestra época está atravesada por presiones relativas a cada detalle de las actividades y relaciones sociales, que dan fe de un sentimiento difuso de justicia y reciprocidad. "Subrayémoslo de nuevo: el derecho reivindicado contra las pretensiones del poder de decidir, según sus imperativos, el incremento de su poderío, no lo ataca de frente, lo alcanza de manera oblicua o, por decirlo así, rodeándolo; apunta a la fuente de la que extrae la justificación de su propio derecho a requerir adhesión y obediencia de todos" (Lefort 2004: 210-211).

Un rasgo de las luchas inspiradas en la noción de derechos es que se desarrollan desde focos diversos, a veces como consecuencia de conflictos coyunturales, luchas que no tienden a fusionarse. No se ordenan bajo la figura de agentes de la historia ni del pueblo uno. De acuerdo con Lefort hay que abandonar la idea de una política que 
comprimiera las aspiraciones colectivas en el modelo de una sociedad-otra "o lo que es equivalente, en la idea de una política que planearía sobre el mundo en que vivimos para dejar caer sobre él los rayos del juicio final"(Lefort 2004: 212). El espíritu revolucionario y el reformismo alimentan las mismas ilusiones, de acuerdo con Lefort: el reformismo supone que el Estado por su propio movimiento o como consecuencia de las luchas populares puede convertirse en un agente del cambio social y promotor de la igualdad; la fe revolucionaria asume que la conquista del Estado y la utilización de sus recursos crearían las condiciones para suprimir la dominación. En ambos casos se muestra la incapacidad de concebir dos movimientos que son indisociables: uno que instala el polo del poder, como separado del conjunto, y aquel que desde este polo, por efecto de esa misma separación acumula medios de dominación de todo género, materiales, conocimientos, derechos de decisión, al servicio de quienes detentan la autoridad. La unidad que pretende disolver las diferencias confunde lo simbólico con lo real, pretende ocultar de una u otra manera la pluralidad, la fragmentación, la heterogeneidad de los procesos de socialización, que la delimitación de un espacio social, constitutiva de una identidad común para aquellos que lo habitan, va acompañada por la referencia a un poder que a la vez surge y se hace garante de ellos. Esa contradicción resiste obstinadamente a su solución, de acuerdo con Lefort, porque es indicio del interrogante que habita la institución misma de lo social. Aquellos que sueñan con la abolición del poder hacen implícitamente referencia a lo que Lefort llama lo uno, imaginan una sociedad reconciliada consigo misma, transparente, en un espacio homogéneo.

Lefort se niega a atribuirle omnipotencia a aquellos poderes anónimos que restringen las libertades en democracia: el Estado (Tocqueville), el capital (Marx) y la tecnología (Heidegger). Desde la sociedad civil y bajo el signo de la exigencia indefinida de las libertades, de una protección mutua de su ejercicio, pueden afirmarse movimientos antagónicos a aquellas fuerzas de dominación. Se da la paradoja de que el pensamiento que denuncia la nivelación en todos los ámbitos de la sociedad actual, está él mismo inclinado a nivelar todo, excluyendo la incertidumbre de la vida de los individuos, de sus relaciones y de las instituciones. Para Lefort, "del extraordinario acontecimiento que supone el surgimiento de la democracia moderna"(Lefort 2004: 125), emerge tanto la libertad política como la libertad individual. Siguiendo a Tocqueville sostiene que esta última no se fundamenta en derechos anteriores a la sociedad. Tanto los derechos políticos como los derechos individuales se instituyen en una forma de sociedad sin referencias últimas de certeza, en los que los fundamentos del poder, del derecho y del conocimiento están abiertos y hacen retroceder indefinidamente los límites de lo posible y lo pensable. En ese contexto, los derechos modernos no se circunscriben a los límites de lo político, afectan a todas las relaciones que los individuos mantienen con el mundo, con los otros y con ellos mismos. La democracia moderna no reduce los derechos humanos a derechos del individuo, así como tampoco a las relaciones entre el Estado y el individuo. Hay que leer en los derechos humanos el signo de la aparición de un tipo de legitimidad y de un espacio público del cual los individuos son tanto producto como productores, espacio que si es asimilado por el Estado da paso a otra forma de sociedad, como ocurre con los regímenes totalitarios. 


\section{Referencias bibliográficas}

Cassirer Ernst (1953), Substance and Function and Einstein's Theory of Relativity. Chicago: Dover Publications, Inc.

Derrida Jacques, Gadamer Hans Georg, Lacoue-Labarthe Phillipe (2014), La conférence de Heidelberg. Lignes, Abbaye d'ardenne.

Gadamer Hans Georg, Derrida Jacques (1989), "Hermeneutics and Logocentrism", Dialogue \& Deconstruction. The Gadamer-Derrida Encounter. New York: State University of New York Press.

García de la Huerta Marcos (2015), “Apoliticismo y carencia de mundanidad. ArendtHeidegger”, Revista de Filosofia Volumen 71. Santiago: Universidad de Chile.

García José Fernando (2015), "Las dos caras de la modernidad. Heidegger y Schmitt", Universum $\mathrm{N}^{\mathrm{o}} \mathbf{3 0}$. Talca: Universidad de Talca.

Habermas Jürgen (2002), Verdad y justiticación. Madrid: Trotta.

Heidegger Martin (2016), La proveniencia del arte y la determinación del pensar. Conferencia dada el 4 de abril de 1967 en la Academia de las ciencia y de las artes de Atenas. Traducción de Breno Onetto (https://www.academia. edu/6719584/ visitada el 22/01/2016).

(2016a), Doctrina de de la verdad según Platón (www.philosophia.cl/ Escuela de Filosofía Universidad ARCIS visitada el 22/01/2016). (2004), Lógica. La pregunta por la verdad. Madrid: Alianza. (1992), Qué es metafísica? y otros ensayos. Buenos Aires: Ediciones Fausto.

(1995), Caminos de Bosque. Madrid: Alianza. (1997), Ser y tiempo. Santiago: Editorial Universitaria. (1995), Seminario de Le Thor. Córdoba: Alción.

(1992), The metaphysical foundations of logic. Indiana: Indiana University Press.

(1998), "La época de la imagen del mundo", Caminos de Bosque. Madrid: Alianza Editorial.

(2003), Filosofia, ciencia y técnica. Santiago: Editorial Universitaria. (2000), Carta sobre el humanismo, Madrid: Alianza Editorial. (2000a), Nietzsche. Tomo II. Barcelona: Ediciones Destino. (1987), De camino al habla. Barcelona: Odós.

Lacoue-Labarthe Phillipe (1989), "Transcendence Ends in Politics" Tipografy. Mimesis, Philosophy, Politics. Masachussets: Harvard University Press.

(2002), La ficción de lo político. Madrid: Arena Libros.

Lacoue-Labarthe Phillipe et Nancy Jean Luc (1997), “Opening Address to the Centre for Philosophical Research on the Political", Retreating the Political. London: Routledge. 
(2000), “'La retirada' de lo político”, Nombres. Revista de Filosofia. Año X, N ${ }^{0}$ 15. Córdoba.

Lafont Cristina (1997), Lenguaje y apertura del mundo. El giro lingüistico en la hermenéutica de Heidegger. Madrid: Alianza.

Lefort Claude (1986), Essais sur le politique. XIX-XX siécles. Paris: Collection Esprit. (2004), La incertidumbre democrática. Barcelona: Antropos.

Marchart Oliver (2007), Post-foundacional Thought: Political difference in Nancy, Lefort, Badiou and Laclau. Edinburgh: Edinburgh University Press.

Nancy Jean Luc (2009), La verdad de la democracia. Buenos Aires: Amorrortu. (2000), La comunidad inoperante. Santiago: LOM/Universidad ARCIS. (2000a) "The surprise of the Event", Being Singular Plural. Stanford: Stanford University Press.

Merleau-Ponty Maurice (1964), Signos. Barcelona: Seix Barral. (2006), Elogio de la filosofía. Buenos Aires: Nueva Visión. (1957), Las aventuras de la dialéctica. Buenos Aires: Leviatán.

Saussure Ferdinand (1995), Cours de linguistique génerale. Paris: Payot \& Rivages. Schmitt Carl (2001), "El concepto de lo político. Texto de 1939”, Carl Schmitt Teólogo de la política. Prólogo y selección de textos Héctor Orestes Aguilar, México: Fondo de Cultura Económica.

(1990), El Leviathan en la teoría del Estado de Tomas Hobbes. Buenos Aires: Editorial Struhart \& Cía. 